\title{
A study on the association between accessory maxillary ostium and maxillary sinus mucosal thickening using cone beam computed tomography
}

Shishir Shetty ${ }^{1 *}$ (D) Saad Wahby Al Bayatti ${ }^{1}$ [D, Natheer Hashim Al-Rawi ${ }^{1}$ (D), Rani Samsudin ${ }^{1}$ (D) Hesham Marei $^{2}$ (D), Raghavendra Shetty ${ }^{3}$ (D) Hossam Abdelatty Abdelmagyd ${ }^{2}$ (D) and Sesha Reddy ${ }^{2}$ (D)

\begin{abstract}
Background: Accessory maxillary ostium (AMO) has a major role to play in the aetiology of maxillary sinusitis. Mucosal thickening is one of the key radiographic features of chronic maxillary sinusitis. The aim of this study was to identify the location of the AMOs and investigate the association between Mucosal Thickening [MT] and AMO using Cone Beam Computed Tomography [CBCT].
\end{abstract}

Methods: CBCT scans of 400 maxillary sinuses from the records of 200 patients who seeked various dental treatments at the Thumbay Dental Hospital, Gulf Medical University, Ajman, United Arab Emirates were evaluated. The incidence, anatomical position and maximal length of accessory maxillary ostia (AMO) in the maxillary antrum were reviewed using CBCT by two examiners. The association between MTs and AMOs were also analysed.

Results: Among the 200 CBCT scans, 131 belonged to male patients and 69 scans belonged to female subjects within the age group of 18-65 years (mean age 41.32 years). AMOs were found in 142 maxillary antra (35.5\%). The interobserver reliability for using $C B C T$ to detect $A M O$ was $(k=0.83)$. There was no significant difference in the frequency of AMOs when the age $(P=0.19)$ and gender $(P=0.54)$ distribution were considered. Sinuses with AMOs, showed significantly greater frequency of MTs $(p=0.001)$. AMOs with maximal length of less than $1 \mathrm{~mm}$ were most commonly observed (51.40\%). AMOs with larger greater maximal length were associated with higher degrees of MT. The location of the AMOs, were not affected by the degree of MT.

Conclusions: The study demonstrates a clear association between degree of MT and occurrence of AMO in the maxillary sinus. However, the location of the AMO is independent of the degree of the MT. There is a greater probability of finding an AMO in the maxillary sinus if the MT in the sinus is more than $3 \mathrm{~mm}$.

Keywords: Maxillary sinus, Nasal cavity, CBCT, Sinusitis, Mucosal thickening, Accessory maxillary ostia

\footnotetext{
* Correspondence: shishirshettyomr@gmail.com

${ }^{1}$ Department of Oral and Craniofacial Health Sciences, College of Dental Medicine, University of Sharjah, Sharjah, United Arab Emirates

Full list of author information is available at the end of the article
}

\section{$\triangle B M C$}

(c) The Author(s). 2021 Open Access This article is licensed under a Creative Commons Attribution 4.0 International License, which permits use, sharing, adaptation, distribution and reproduction in any medium or format, as long as you give appropriate credit to the original author(s) and the source, provide a link to the Creative Commons licence, and indicate if changes were made. The images or other third party material in this article are included in the article's Creative Commons licence, unless indicated otherwise in a credit line to the material. If material is not included in the article's Creative Commons licence and your intended use is not permitted by statutory regulation or exceeds the permitted use, you will need to obtain permission directly from the copyright holder. To view a copy of this licence, visit http://creativecommons.org/licenses/by/4.0/ The Creative Commons Public Domain Dedication waiver (http://creativecommons.org/publicdomain/zero/1.0/) applies to the data made available in this article, unless otherwise stated in a credit line to the data. 


\section{Background}

Chronic maxillary sinusitis [CMS] is one of the most common disease conditions that takes a patient to the otolaryngologist [1]. CMS has a multifactorial etiology ranging from bacterial infection and allergy to nasal anatomical variations [1]. Accessory maxillary ostium [AMO] is believed to play a role in CMS aetiology [2]. Some researchers believe that mucous that has been drained through primary ostium may re-enter into the maxillary sinus through the AMO leading to "mucus recirculation" [3, 4]. However other researchers state that AMO develops following an acute maxillary sinusitis. Therefore, whether AMO is the cause or the result of maxillary sinusitis, is still uncertain. It is also debatable whether AMO is congenital or acquired [5]. There has been a significant correlation between AMO and CMS in previous studies carried out using computed tomography $[6,7]$.

Symptoms of maxillary sinusitis may sometimes appear in the maxillary dento-alveolar region and Cone Beam Computed tomography [CBCT] may be performed as part of dental investigation. This increases the possibility for a dental surgeon, finding an AMO during evaluation of the CBCT scans. While Computed Tomography $[\mathrm{CT}]$ offers superior image, quality compared to $\mathrm{CBCT}$, the latter exposes the patient to a substantially lower radiation dose [8]. The aim of this study was to identify the location of the AMOs and investigate the association between Mucosal Thickening [MT] and AMO.

\section{Material and methods}

CBCT images from 200 patients $(n=400$ maxillary sinuses) who underwent maxillofacial scans at Thumbay Dental Hospital, Gulf Medical University, Ajman, United Arab Emirates [UAE] were evaluated in this retrospective study. Human Ethical Approval was obtained from the Institutional Review Board of the Gulf Medical University (Ref. no. INT/COD/FR/006-2020). The CBCT image examinations of the sino-nasal variants were performed using a ProMax 3D Mid machine (Planmeca, Helsinki, Finland), operated at $90 \mathrm{kVp}$ and $10 \mathrm{~mA}$ with a $9 \times 16 \mathrm{~cm}$ field of view. Assessment of CBCT scans was performed directly on a $1920 \times 1080$ pixel and 23-inch DELL monitor screen. The voxel edge length was $0.2 \mathrm{~mm}$.

CBCT scans of male and female subjects within the age range of 18 to 65 years were included in the study. The maxillary dental status was classified as dentate, partially edentulous, and completely edentulous. The classification was based on the presence or absence of teeth distal to maxillary canine till the maxillary third molar bilaterally.

CBCT scans of improper quality were excluded from the study, these included streak artifacts $(n=4)$, incomplete images $(n=2)$. Exclusion criteria for patients in this study were for subjects who had a history of midfacial trauma $(n=2)$, tumour $(n=1)$, cleft palate $(n=1)$, and syndromes effecting the midface $(n=1)$. All selected CBCT scans of the study were evaluated by two radiologists (A) and (B) with more than ten years of clinical experience in dento-maxillofacial radiology. In case of inter-observer disagreement, a third oral radiologist (C) with equivalent clinical experience was consulted for the final decision.

In order to identify and confirm the existence of the AMO, the examiners used coronal Fig. 1A, axial Fig. 1B and sagittal views Fig. 1C. Horizontal and vertical annotation overlays directed the radiologist to correctly display the AMO in all three planes. Inter-observer reliability was evaluated using Cohen Kappa test.

The vertical and antero-posterior measurements for the location of AMO was determined by using the technique suggested by Butaric et al. [9]. The distance of the AMO from the floor of the sinus (C) was calculated using the coronal $\mathrm{CBCT}$ sections, by measuring the distance between 2 horizontal lines A1-A (passing through the most inferior point of the AMO) and B1-B (passing

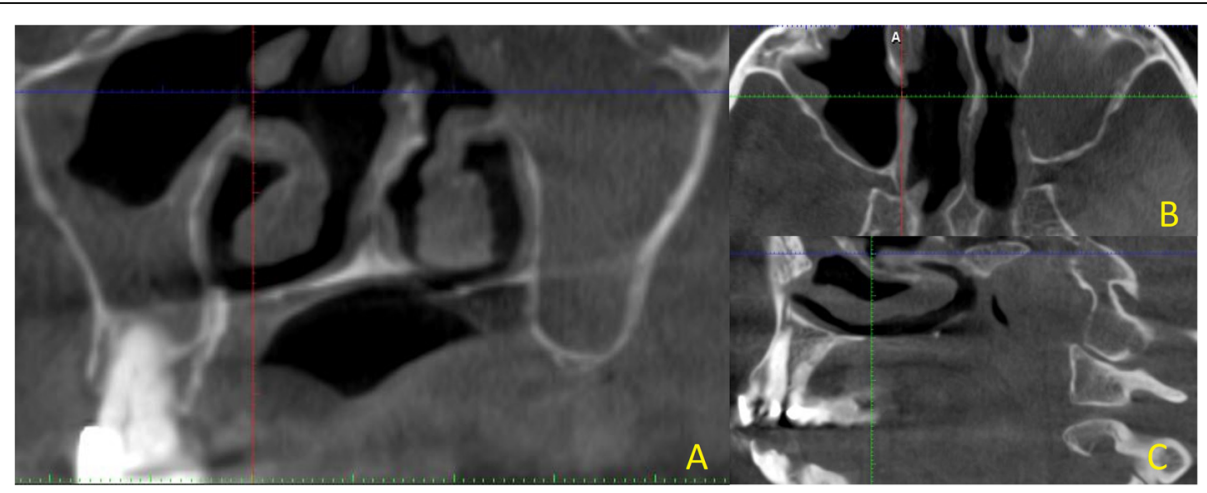

Fig. 1 A coronal $C B C T$ section showing $A M O$ in the right maxillary sinus, deviation of the nasal septum and mucosal thickening in the floor of the sinus. $\mathbf{B}$ corresponding axial and $\mathbf{C}$ sagittal section. Coloured linear annotations are used to precisely locate the site of AMO in all three planes 
through the most inferior point on the floor of the maxillary sinus) Fig. 2. The antero-posterior location of the AMO was evaluated on the axial CBCT sections by measuring the distance (D) between 2 horizontal lines F1-F (passing through the most anterior point of the $\mathrm{AMO}$ ) and E1- E (passing through the most anterior point of the sinus) Fig. 3. The longest dimension of AMO in the sagittal CBCT segment was measured as suggested by Hung et al. Fig. 4 [10].

The MT was evaluated and classified based on criteria used by Sheiki et al. [11]. According to the classification, MTs were classified as Type $1(<1 \mathrm{~mm})$, Type $2(1-3$ $\mathrm{mm})$, Type $3(3-6 \mathrm{~mm})$, Type $4(6-10 \mathrm{~mm})$, Type $5(>10$ $\mathrm{mm})$. According to the criteria the MT is measured at six points in each of the sinuses. The mesial and distal sides of the second premolar and first and second molar teeth were the six points of measurement. Among these six points, the highest point of the thickened mucosa of the sinus floor was considered to be the representative value of MT for that sinus Fig. 5. In the edentulous cases measurement of MT was performed at six equidistant points on a line connecting most of the anterior and posterior points on the sinus floor in the sagittal section Fig. 6. Only MT in the floor of the sinus was considered in our study.

\section{Data analysis}

The data obtained regarding the occurrence, anatomical location, maximal length of AMOs and their association

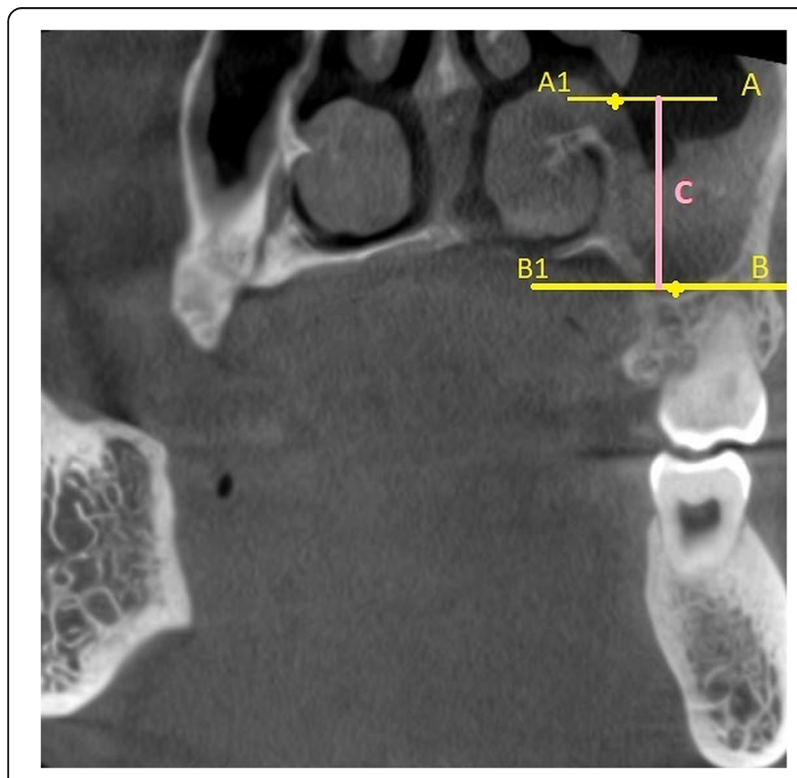

Fig. 2 Coronal CBCT section showing method used to determine the location of $A M O$ in vertical dimension $(C)$. The distance $C$ is obtained by measuring the distance between 2 horizontal lines A1-A (passing through the most inferior point of the $\mathrm{AMO}$ ) and $\mathrm{B} 1-\mathrm{B}$ (passing through the most inferior point on the floor of the maxillary sinus)

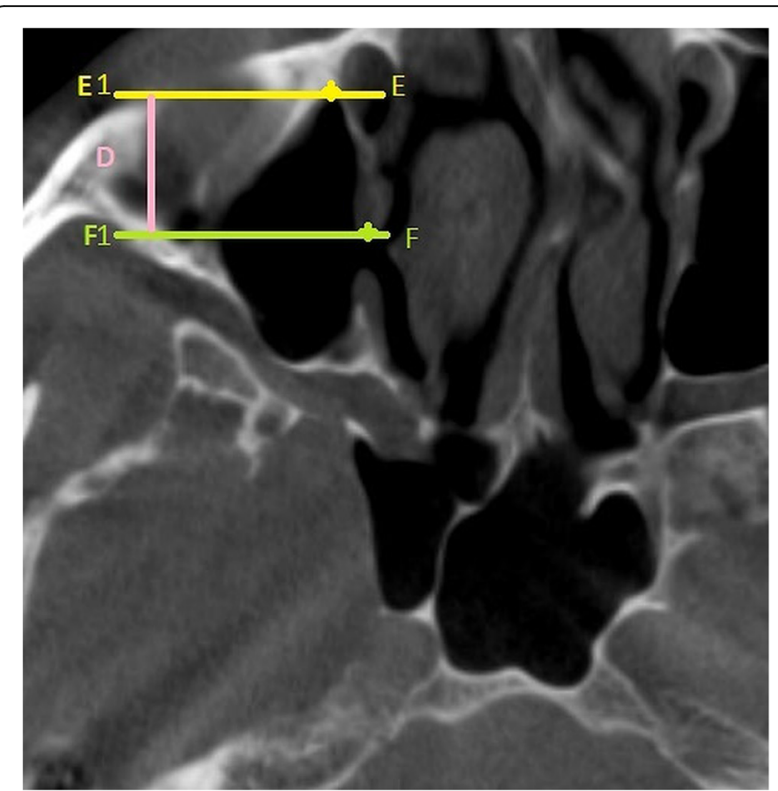

Fig. 3 Axial $C B C T$ section showing method used to determine the location of AMO in antero-posterior dimension (D). The distance (D) is obtained by measuring the distance between 2 horizontal lines F1-F (passing through the most anterior point of the AMO) and E1$\mathrm{E}$ (passing through the most anterior point of the sinus)

with MTs were evaluated using IBM SPSS statistics (Version 22, Armonk. NY: IBM Corp). Chi Square test and Fisher Exact Test were used to determine difference among study groups., Spearman's Rho was used, to evaluate the association between the study groups.

\section{Results}

In the present study, 400 maxillary sinuses from a total of 200 CBCT scans were evaluated for the presence of AMO. Among the 200 CBCT scans 131 (262 maxillary sinuses) belonged to male subjects and 69 scans (138

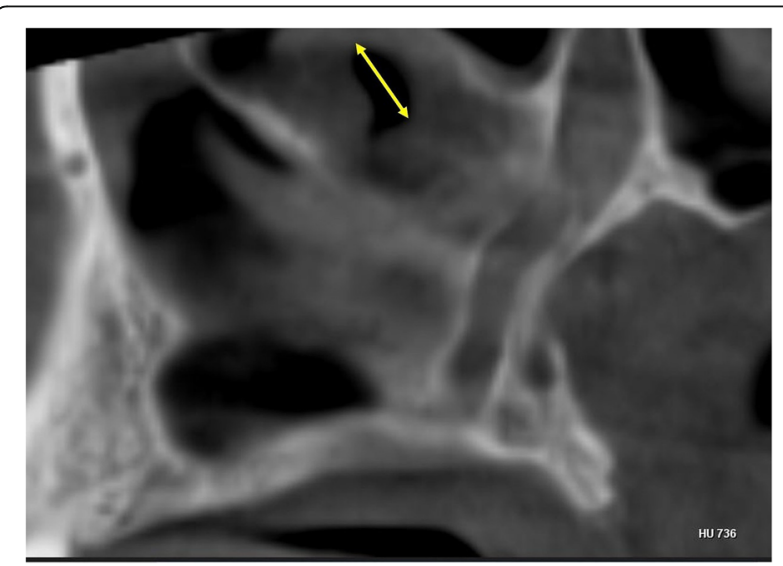

Fig. 4 Two-sided yellow arrow depicting the maximal length of the AMO located on the lateral nasal wall observed in the sagittal CBCT section 


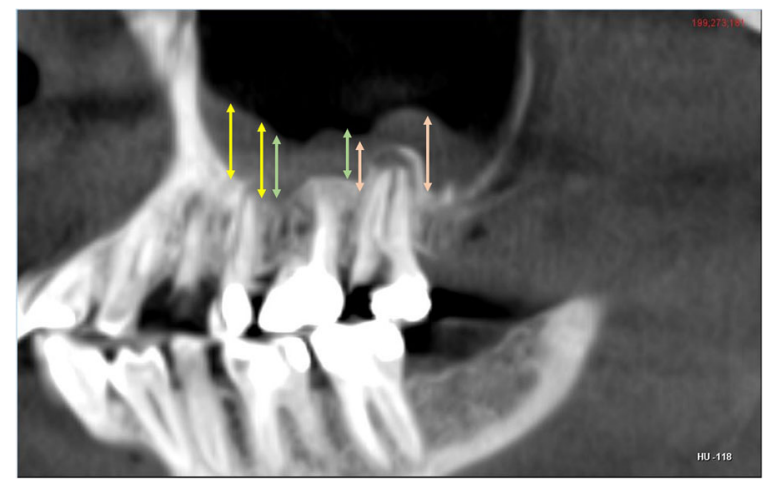

Fig. 5 Sagittal section showing the points at which the mucosal thickening was measured in dentate study subjects. The mesial and distal sides of the second premolar (yellow arrows), first molar (green arrows) and second molar (pink arrows) were the six points of measurement

maxillary sinuses) belonged to female subjects. The age range of the subjects in the present study was between 22 and 65 years with the mean of 41.32 years. On evaluation of the dental status, revealed that 157 subjects were dentate, 40 were partially dentate and 3 were completely edentulous.

Two oral radiologists evaluated the presence, location and characteristics of the AMOs using multiplanar views of CBCT scans. The inter observer reliability using Cohens Kappa test was 0.83 . We used the rubrics by Regier et al. 2012 for kappa rating [11]. The intra- observer reliability for detecting the presence of AMO was 0.85 for the oral radiologist $\mathrm{A}$ and 0.79 for $\mathrm{B}$.

AMOs were found in 142 of the 400 maxillary sinuses. Primary maxillary ostium [PMO] was patent in 392 (98\%) of the 400 maxillary sinuses. A total of 142 AMOs were found, 90 AMOs were found in male subjects and 52 in female subjects. There was no statistically

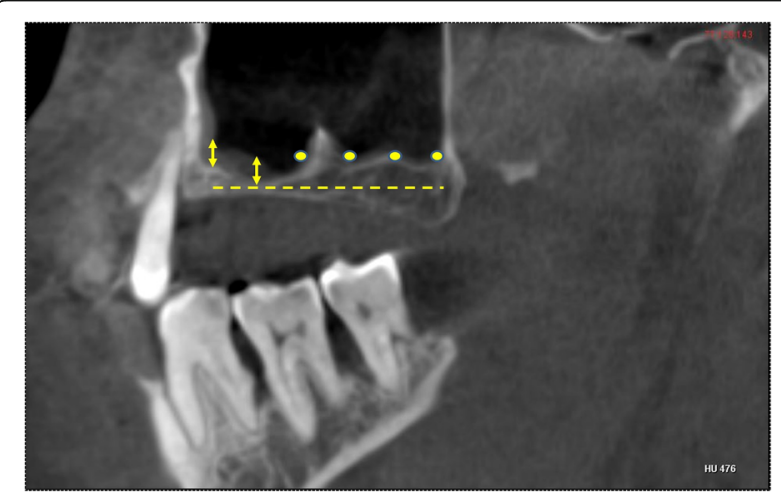

Fig. 6 Sagittal CBCT section showing the points at which measurements were made in a edentulous study subject. Six equidistant points (arrows and dots) on a line (yellow discontinuous) connecting the anterior and posterior most points on the floor of the sinus in sagittal section. (Dots indicate areas with no MT) significant gender difference in the occurrence of AMO $[\mathrm{OR}=1.1306, P=0.54$ (95\% CI: 0.7596 to 1.6827 ).

There was a radiographic evidence of obstruction of the PMO in eight maxillary sinuses. Among the eight maxillary sinuses with PMO obstruction, six sinuses showed the presence of AMO whereas two did not reveal the presence of AMO. The maximal length of the AMOs in the sagittal section varied from $0.5 \mathrm{~mm}$ to $7 \mathrm{~mm}$. The AMOs were categorised into Class I, II and III based on their maximal length. On evaluation of the AMOs, 73 (51.40\%) were less than $2 \mathrm{~mm}$ in length (Class I), $56(39.43 \%)$ were 2-4 mm in size (Class II), whereas $13(9.15 \%)$ were greater than $4 \mathrm{~mm}$ in size (Class III).

MT was observed among 132 of the 400 maxillary sinuses that were evaluated. When maxillary sinuses with AMOs $(n=142)$ were evaluated for the presence of MT, 96 maxillary sinuses (67\%) had evidence of MT, while 36 maxillary sinuses (33\%) had no radiographic evidence of MT. When the maxillary sinuses without AMOs $(n=258)$ were examined, it was found that 36 maxillary sinuses had radiographic evidence MT, while 222 sinuses had no radiographic evidence of $\mathrm{MT}$. In sinuses with AMOs, there was a significantly higher occurrence of MTs [ $P<$ $0.0001 \mathrm{OR}=0.2064$ (95\% CI: 0.1337 to 0.3187 ).

When the size of MTs were categorized according to criteria defined by Sheiki $M$ et al., it was noted that 47 (35.6\%) sinuses belonged to Type 1, 35 (26.5\%) sinuses belonged to Type 2, 32 (24.2\%) sinuses belonged to Type 3, 12 sinuses belonged to Type 4 and 6 sinuses belonged to Type 5 . Figure 7. Type 3 MT had the highest occurrence of AMOs followed by types 1, 2, 4 and 5 . Figure 8.

There was a significant $(P=0.006)$ association between the occurrence of AMOs and types of MT (Table 1). On post hoc comparison, there was a significant difference in the occurrence of AMOs between Type 1 and Type $3(p<0.001)$, Type $4(p<0.001)$, Type $5(p<0.001)$. Similarly, there was a significant difference in occurrence of AMOs between MT of type 2 and Type 3(p=0.02), Type

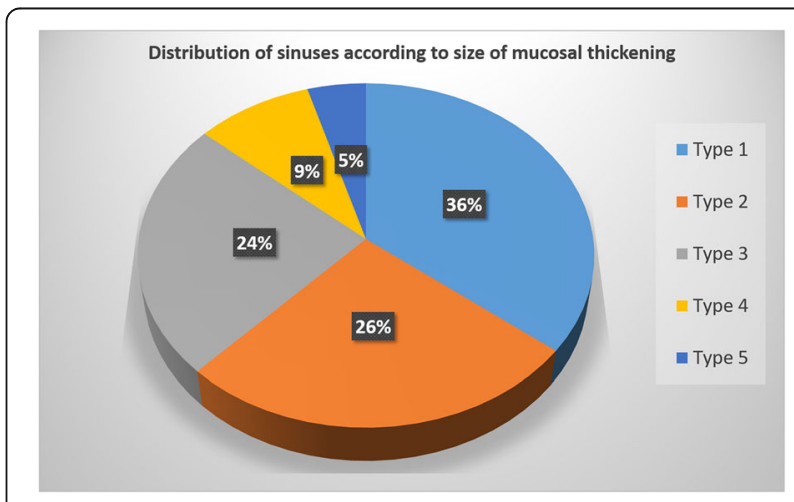

Fig. 7 Distribution of the types of mucosal thickenings in maxillary sinuses of study subjects 


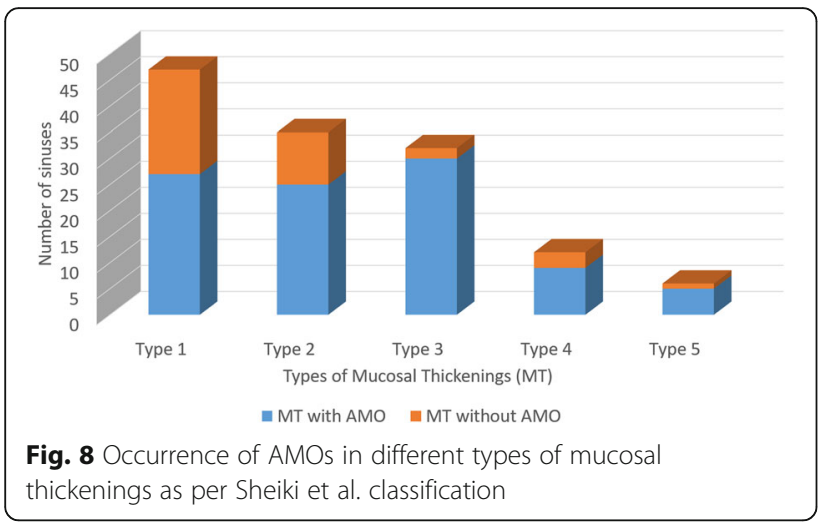

4. $(p=0.05)$, Type $5(p=0.05)$. However, there was no statistically significant difference in the occurrence of AMOs between MT of Type 1 and $2(p=0.07)$. Similarly, there was no statistically significant difference in the occurrence of AMO between MT of Types 3 and Type $4(p=0.24)$, Type 4 and Type $5(p=0.07)$ (Table 2$)$. No significant correlation was observed between the occurrence of AMOs and type of MT was observed $\left(\mathrm{r}_{\mathrm{s}}=\right.$ -0.7, $P=0.18812$ ).

The mean distance from the most inferior point on the floor of the sinus to the inferior border of AMO in the coronal CBCT sections was $19.93 \pm 1.68 \mathrm{~mm}$. On overall and post hoc comparison, there was no significant difference in the mean distance among the different types of MT (Tables 3 and 4). There was no significant correlation between the mean distance of AMO from the sinus floor and type of MT $\left(r_{s}=0.3, P=0.62384\right)$.

The mean distance of the anterior most point of AMO to the anterior most point of the maxillary sinus in the axial section was $15.39 \pm 1.82 \mathrm{~mm}$. Overall comparison and post hoc comparison revealed that there was no significant difference in the mean distance of the AMO among different types of MT on (Tables 5 and 6). There was no significant correlation between the distance of AMO from the anterior-most point sinus and type of MT $\left(\mathrm{r}_{\mathrm{s}}=-0.5, P=0.391\right)$.

Table 1 Overall comparison of the AMO among different types of MT as per Sheiki et al's classification

\begin{tabular}{|c|c|c|c|c|}
\hline \multirow{2}{*}{$\begin{array}{l}\text { Types } \\
\text { of MT }\end{array}$} & \multicolumn{2}{|l|}{ AMO } & \multirow{2}{*}{$\begin{array}{l}\text { Total } \\
\text { sinuses }\end{array}$} & \multirow{2}{*}{$\begin{array}{l}\text { Fisher's Exact Test } \\
p \text {-value }\end{array}$} \\
\hline & Present & Absent & & \\
\hline No MT & 36 (13.4\%) & $232(86.5 \%)$ & $268(100 \%)$ & $0.006^{*}$ \\
\hline Type 1 & 27 (57.4\%) & 20 (42.6\%) & 47 (100\%) & \\
\hline Type 2 & 25 (71.4\%) & $10(28.6 \%)$ & 35 (100\%) & \\
\hline Type 3 & 30 (93.8 \%) & 2 (6.3\%) & 32 (100\%) & \\
\hline Type 4 & 9 (75 \%) & $3(25 \%)$ & 12 (100\%) & \\
\hline Type 5 & 5 (83.3 \%) & $1(16.7 \%)$ & 6 (100\%) & \\
\hline
\end{tabular}

${ }^{*} p<0.05$ Statistically Significant, $p>0.05$ Non-Significant, NS
Table 2 Post hoc comparison of the occurrence of AMOs among different types of MT as per Sheiki et al's classification

\begin{tabular}{lllll}
\hline Type of $\mathbf{M T}$ & Type 2 & Type 3 & Type 4 & Type 5 \\
\hline Type 1 & $0.19(\mathrm{NS})^{\mathrm{a}}$ & $<0.001^{* a}$ & $<0.001^{* \mathrm{a}}$ & $<0.001^{\mathrm{b}}$ \\
Type 2 & & $0.02^{* \mathrm{a}}$ & $0.05^{\mathrm{b}}$ & $0.05^{\mathrm{b}}$ \\
Type 3 & & $0.12(\mathrm{NS})^{\mathrm{b}}$ & $0.41(\mathrm{NS})^{\mathrm{b}}$ \\
Type 4 & & & $1.00(\mathrm{NS})^{\mathrm{b}}$ \\
\hline${ }^{\mathrm{a}}$ Chi Square test & & & \\
${ }^{\mathrm{b}}$ Fisher Exact Test \\
${ }^{*} p<$ 0.05 Statistically Significant, $p>0.05$ Non-Significant, NS
\end{tabular}

A statistically significant $(P=0.001)$ association was observed between the maximal length of AMOs and the type of MT. Class 1 AMOs were predominantly found with Type 3 MT, Type 2 MT and no MT. Class 2 AMOs were predominant in Type 1 and Type 2 MTs. Class 3 were predominant in Type 4 and 5 MTs (Table 7).

\section{Discussion}

The main findings of this study revealed that the AMOs are likely to be located at approximately $19 \mathrm{~mm}$ from the inferior most point on the floor of the sinus. The maxillary sinuses with AMOs, showed significantly greater frequency of MTs. AMOs with greater maximal length were associated with higher degrees of MT. However, the location of the AMOs, were not affected by the degree of MT.

To discuss the clinical relevance and findings of our study it is important to note that maxillary sinus is an anatomic structure located in a vital location with close proximity to nasal cavity and the roots maxillary posterior teeth [12]. Maxillary sinuses are often associated with anatomic variations particularly the osteo-meatal complex which predisposes them to disease conditions [13]. $\mathrm{AMO}$ is one among the variations of the osteo-meatal complex. It is important to note that sinus disease does not necessarily mean the presence of osteo-meatal variation [14]. The term AMO was first coined in the year 1993 by Rice and Scheaffer, as a terminology for all the openings on the lateral nasal wall, other than a single primary ostium. [15]. It is not very clear whether AMO is congenital or acquired. Some researchers believe that AMOs usually occurs after an episode of acute maxillary sinusitis [16]. Some recent studies have highlighted the "recirculating mucus ring" phenomenon in which mucus circulation takes place between the normal ostium and the maxillary sinus AMO [3]. Apart from routine imaging procedures nasal endoscopy has been used for the detection of AMO $[17,18]$.

In our study, $35.5 \%$ of the maxillary sinuses in the population were found to have AMOs. The prevalence of AMOs was examined in hospital / clinic settings using computerized tomography (CT) and endoscopy, while in anatomical research, cadavers were assessed. AMOs 
Table 3 Overall comparison of the mean distance between the floor of the sinus to the AMO in different types of MT as per Sheiki et al's classification

\begin{tabular}{|c|c|c|c|}
\hline \multirow[t]{2}{*}{$\begin{array}{l}\text { Types Mucosal } \\
\text { Thickening }\end{array}$} & \multirow[t]{2}{*}{ Number of sinuses in each group } & $\begin{array}{l}\text { Mean distance of the AMO from the floor of the sinus } \\
\text { in coronal CBCT section ( } \mathrm{mm}=\text { millimetres) }\end{array}$ & \multirow{2}{*}{$\begin{array}{l}\text { Fisher's Exact Test } \\
p \text {-value }\end{array}$} \\
\hline & & $\operatorname{Mean}(\mathrm{mm})$ & \\
\hline No mucosal thickening & 36 & $18.95 \pm 2.45$ & 0.32 \\
\hline Type 1 & 27 & $20.23 \pm 1.06$ & \\
\hline Type 2 & 25 & $18.56 \pm 2.13$ & \\
\hline Type 3 & 30 & $21.85 \pm 1.93$ & \\
\hline Type 4 & 9 & $19.07 \pm 0.78$ & \\
\hline Type 5 & 5 & $20.96 \pm 1.78$ & \\
\hline Total & 132 & $19.93 \pm 1.68$ & \\
\hline
\end{tabular}

were present in $29.5 \%$ of paranasal CT scans of the research cohort in one published study on the Jordanian population [7]. Recent CT based studies on AMOs reported a prevalence $19.1-46.3 \%$ of the sinuses in Turkish population and $18 \%$ in Indian population $[6,19,20]$. In another CT and endoscopy-based research on the Indian population conducted in 2018, AMOs were found in $23 \%$ of the cohort [1]. Similar percentages were reported by purely endoscopic studies in the Indian population [18]. AMOs were reported in 13.8-26\% of the cadavers as per few recently study published anatomical studies. [15, 21-24]. Studies carried out on Chinese, Indian and Turkish population revealed prevalence rates of AMOs to be $47.2 \%, 23.7$ and $38.8 \%$, respectively [10, 25, 26]. In general, the prevalence of AMOs ranges from 20 to $50 \%$ in studies using CT, CBCT scans and endoscopy. The likely explanations for this difference may be ethnic difference and the sensitivity of investigative imaging system. However, cadaveric studies have shown a lower prevalence of AMOs relative to studies using live subjects using CT, CBCT, or endoscopy. Post mortem anatomical distortion may be the likely cause for this lower prevalence [27]. Therefore, prevalence studies using imaging are more reliable.

Intra- and inter observer agreement is a vital issue in medical imaging interpretation and this must be assessed

Table 4 Post hoc comparison of the mean distance of the $\mathrm{AMO}$ from the sinus floor among different types of MT as per Sheiki et al's classification

\begin{tabular}{llllll}
\hline Type of MT & Type 1 & Type 2 & Type 3 & Type 4 & Type 5 \\
\hline No MT & $0.07(\mathrm{NS})^{\mathrm{a}}$ & $1.26(\mathrm{NS})^{\mathrm{a}}$ & $0.07(\mathrm{NS})^{\mathrm{a}}$ & $0.13(\mathrm{NS})^{\mathrm{b}}$ & $0.3(\mathrm{NS})^{\mathrm{b}}$ \\
Type 1 & & $0.26(\mathrm{NS})^{\mathrm{a}}$ & $<0.17(\mathrm{NS})^{\mathrm{a}}$ & $<0.62(\mathrm{NS})^{\mathrm{b}}$ & $1.00(\mathrm{NS})^{\mathrm{b}}$ \\
Type 2 & & & $0.08(\mathrm{NS})^{\mathrm{a}}$ & $0.24(\mathrm{NS})^{\mathrm{b}}$ & $0.07(\mathrm{NS})^{\mathrm{b}}$ \\
Type 3 & & & & $0.41(\mathrm{NS})^{\mathrm{b}}$ & $1.00(\mathrm{NS})^{\mathrm{b}}$ \\
Type 4 & & & & & $0.07(\mathrm{NS})^{\mathrm{b}}$ \\
\hline
\end{tabular}

${ }^{\mathrm{a} C h i}$ Square test

${ }^{\mathrm{b}}$ Fisher Exact Test

$p<0.05$ Statistically Significant, $p>0.05$ Non-Significant, NS with the most suitable test for an accurate outcome of any imaging study [28]. In our study the inter observer reliability was 0.83 and intra-observer reliability for detecting the presence of AMO was 0.85. The observers' reliability values in our study were consistent with the values found in the study by Hung et al. [10]. Nevertheless, few other researchers did not evaluate the components of inter and intra observer variability in their studies [6].

In our study there was no statistically significant difference in the occurrence of AMOs between male and female subjects, although the occurrence was numerically higher in male subjects. Similar observations were found in the studies by Bani-Ata et al. and Ghosh et al. [1, 7]. However, Hung $\mathrm{K}$ et al. [10] found AMOs to be more commonly present in, CBCT scans of female subjects. It is important to note that there was no statistical difference in terms of gender in any of the studies reiterating the fact that, gender had no significant influence on the occurrence of AMO [1, 7].

We found no statistically significant difference in the occurrence of AMOs when age was considered. The mean age of the research subjects was higher than that of the Hussein et al. and Sahin et al. studies [29, 30]. In most studies, the frequency of AMOs has not been significantly dependent on the age group $[1,6,7,17]$. However, there was a higher prevalence of AMOs in older age groups in one study by Dedeoğlu $\mathrm{N}$ and Altun $\mathrm{O}$. The authors attributed the greater incidence of AMOs in the elderly to be due to the age-related phenomenon and the resorption phenomenon that accompanied agerelated edentulism [25].

In our study majority of the AMOs (90.83\%) were less than $4 \mathrm{~mm}$ in size. This was consistent with the findings of Hung $\mathrm{K}$ et al. [10]. Based on the maximal length, we divided the AMOs into three classes in our study. We also identified the location of the AMO based on its distance from the floor and the anterior wall of the maxillary sinus. The location of the AMO was determined by some of the studies and case reports based on the 
Table 5 Overall comparison of the mean distance between the anterior most point of the maxillary sinus to the AMO among different types of MT as per Sheiki et al's classification

\begin{tabular}{llll}
\hline $\begin{array}{l}\text { Types of } \\
\text { Mucosal } \\
\text { Thickening }\end{array}$ & $\begin{array}{l}\text { Number of sinuses in } \\
\text { each group }\end{array}$ & $\begin{array}{l}\text { Mean distance of the AMO from the anterior most point in the maxillary sinus } \\
\text { in axial section }(\mathbf{m m}=\text { millimeters }) \\
\text { Mean }(\mathbf{m m})\end{array}$ & $\begin{array}{l}\text { Fisher's } \\
\text { Exact Test } \\
\boldsymbol{p} \text {-value }\end{array}$ \\
\hline $\begin{array}{l}\text { No mucosal } \\
\text { thickening }\end{array}$ & 36 & $14.32 \pm 1.75$ \\
Type $\mathbf{1}$ & 27 & $16.54 \pm 2.06$ \\
Type $\mathbf{2}$ & 25 & $15.27 \pm 1.05$ \\
Type $\mathbf{3}$ & 30 & $14.92 \pm 1.86$ \\
Type $\mathbf{4}$ & 9 & $16.07 \pm 2.01$ \\
Type $\mathbf{5}$ & 5 & $15.22 \pm 2.21$ \\
Total & 132 & $15.39 \pm 1.82$ \\
\hline
\end{tabular}

landmarks on the lateral nasal wall, such as the anterior and posterior fontanelle [1,10,31-33]. Other studies have identified the location of the ostium based on their distance from the landmarks such as floor of the sinus and anterior wall of the sinus $[9,34,35]$. Due to the variability of landmarks on the lateral nasal wall, we chose the latter approach based on measurements [36, 37]. In our study the height of the AMO from the floor of the sinus was $19.93 \pm 1.68 \mathrm{~mm}$. Radiographical studies have shown that the normal maxillary sinus height varies from $28 \mathrm{~mm}$ to $34 \mathrm{~mm}[38,39]$. Following the above measurements, AMOs are most likely to be found at a point between half and three-fourths of a line connecting the floor of the sinus to the roof. The fragility of the lateral nasal wall in this area might be the explanation for the incidence of AMOs at this site [40]. During inflammation, the maxillary sinus is almost half filled with inflammatory fluid in gel consistency. The cohesive forces prohibit normal ciliary transport of the fluid into the ostium, which is situated at a higher level. Therefore, the fluid content finds a point of structural fragility on the lateral nasal wall to escape the sinus [40].

MT is associated with collection of inflammatory fluid within the maxillary sinus [41-43]. Many recent studies have highlighted the relationship between periapical and periodontal health of maxillary dentition, sinus floor

Table 6 Post hoc comparison of the mean distance of the $\mathrm{AMO}$ from the anterior wall of the maxillary sinus among different types of MT as per Sheiki et al's classification

\begin{tabular}{llllll}
\hline Type of MT & Type 1 & Type 2 & Type 3 & Type 4 & Type 5 \\
\hline No MT & $0.07(\mathrm{NS})^{\mathrm{a}}$ & $1.26(\mathrm{NS})^{\mathrm{a}}$ & $0.07(\mathrm{NS})^{\mathrm{a}}$ & $0.13(\mathrm{NS})^{\mathrm{b}}$ & $0.3(\mathrm{NS})^{\mathrm{b}}$ \\
Type 1 & & $0.26(\mathrm{NS})^{\mathrm{a}}$ & $<0.17(\mathrm{NS})^{\mathrm{a}}$ & $<0.62(\mathrm{NS})^{\mathrm{b}}$ & $1.00(\mathrm{NS})^{\mathrm{b}}$ \\
Type 2 & & & $0.08(\mathrm{NS})^{\mathrm{a}}$ & $0.24(\mathrm{NS})^{\mathrm{b}}$ & $0.07(\mathrm{NS})^{\mathrm{b}}$ \\
Type 3 & & & & $0.41(\mathrm{NS})^{\mathrm{b}}$ & $1.00(\mathrm{NS})^{\mathrm{b}}$ \\
Type 4 & & & & & $0.07(\mathrm{NS})^{\mathrm{b}}$ \\
\hline
\end{tabular}

${ }^{\mathrm{a} C h i}$ Square test

${ }^{b}$ Fisher Exact Test

${ }^{*} p<0.05$ Statistically Significant, $p>0.05$ Non-Significant, NS mucosa and maxillary sinusitis [44]. There are many approaches used by researchers to classify mucosal thickening in the maxillary sinus using CT and CBCT [4547]. Magnetic resonance imaging (MRI) was also used in one of the earlier studies for the classification of MT in the maxillary sinus $[48,49]$. MT has been graded by researchers either on the basis of thickening (mild/ moderate / severe, polyps, pseudocyst retention) or on the basis of numerical measurement ranges [11, 43]. We used Sheiki et al's classification, which is based on measurements. In the present study, there was a statistically significant difference in the occurrence of AMOs when the thickening size exceeded $3 \mathrm{~mm}$. It is important to note that, there is no consensus on the threshold values above which MT is considered to be pathological [50]. In our study, sinuses with radiographic evidence of MT, showed significantly higher occurrence of AMOs than

Table 7 Association and between the classes of AMO as per Hung et al's classification and types of MT as per Sheiki et al's classification

\begin{tabular}{lllll}
\hline & \multicolumn{2}{l}{ Length of AMO } & Total \\
\cline { 2 - 4 } & Class 1 & Class 2 & Class 3 & \\
\hline No Mucosal thickening (MT) & 24 & 19 & 3 & 46 \\
& $52.2 \%$ & $41.3 \%$ & $6.5 \%$ & $100.0 \%$ \\
Type 1- Mucosal thickening & 10 & 16 & 1 & 27 \\
& $37.0 \%$ & $59.3 \%$ & $3.7 \%$ & $100.0 \%$ \\
Type 2- Mucosal thickening & 14 & 10 & 1 & 25 \\
& $56.0 \%$ & $40.0 \%$ & $4.0 \%$ & $100.0 \%$ \\
Type 3- Mucosal thickening & 27 & 2 & 1 & 30 \\
& $90.0 \%$ & $6.7 \%$ & $3.3 \%$ & $100.0 \%$ \\
Type 4- Mucosal thickening & 2 & 2 & 5 & 9 \\
& $22.2 \%$ & $22.2 \%$ & $55.6 \%$ & $100.0 \%$ \\
Type 5- Mucosal thickening & 1 & 2 & 2 & 5 \\
\hline \multirow{2}{*}{ Fishers Exact test } & $20.0 \%$ & $40.0 \%$ & $40.0 \%$ & $100.0 \%$ \\
\hline
\end{tabular}


those without such features. Similar results were obtained in a CT based study by Gusrov $\mathrm{M}$ et al., who suggested that AMO may be an accelerating factor in the transformation of sinus mucosal pathologies like retention cyst to antrochoanal polyps [19]. This association was also reflected in endoscopy-based and CBCT studies which revealed higher frequency of occurrence of AMOs in rhinosinusitis patients [17, 30, 51]. A CT-based analysis by Yenigun A et al. concluded that a probability of finding MT in the same sinus was correlated with the existence of AMOs. Additional observations from our study also suggest that the probability of finding an AMO during the radiographic evaluation of the maxillary sinus is higher if there is co-existing mucosal thickening of more than $3 \mathrm{~mm}$ in the sinus floor. Such results suggest the Acquired Development Hypothesis model for the existence of AMO rather than the theory of congenital development. The length of the ostium plays a major role in the mucous circulation and thus will influence the mucosal thickening of the maxillary sinus. If the size of the AMO is up to $4 \mathrm{~mm}$, the mucous secretions with a normal viscidness tend to circumvent the $\mathrm{AMO}$ in the maxillary sinus. In this situation the secretions do not pass through the AMO. However, the same phenomenon does differ for situations where the size of the AMO exceeds $4 \mathrm{~mm}$ in diameter, whereby the mucous secretion portion of the mucous carpet flowing over the centre of the AMO flows into the centre of the meatus. The part of the mucous secretions in the margin of the AMO continues to pass along its borders of the AMO to finally reach the main natural ostium. The mucous secretions that have moved out of the maxillary sinus, through the main natural ostium, return to the same maxillary sinus when it makes a downward journey due to gravity and encounters AMO on its path. The secretions are laden with pathogenic micro-organisms from the nasal cavity layer during the re-entry process into the maxillary sinus. This malicious recirculation of secretions regularly aggravates the sinus condition, causing the sinus mucosa to pathologically thicken $[2,16]$.

Our study revealed that the MT did not have any statistically significant correlation with the location of the AMO. However, when we evaluated the maximal length the of AMOs with the type of MT, it was observed that larger AMOs were associated with higher degree of MT. This was similar to the observation in the study by Hung $\mathrm{K}$ et al. [10]. They proposed that AMO decreases the clearance of mucus secretions in the corresponding maxillary sinus, which could make the sinus susceptible to pathologies $[6,10]$.

Although the study establishes association between $\mathrm{AMO}$ and MT, there are some shortcomings that can be addressed in future studies. Future studies can be conducted with clinical and imaging findings, since clinical correlation is desirable to avoid over diagnosis of mucosal thickening based purely on imaging findings [42].

\section{Conclusion}

The study findings indicate that the location of the AMO is independent of the degree of the MT. However, the occurrence of AMO is associated with degree of MT. Higher degrees of mucosa thickening are correlated with larger AMOs. The findings also show that there is a greater chance of discovering an AMO if the MT in the sinus is more than $3 \mathrm{~mm}$. The findings of our study demonstrate the possibility of using CBCT to assess the occurrence and location of AMO in the osteo-meatal complex. It also encourages the use of CBCT in otolaryngology as a substitute for CT for imaging osteomeatal complex with comparatively lower doses of radiation.

\section{Supplementary Information}

The online version contains supplementary material available at https://doi. org/10.1186/s13005-021-00284-0.

Additional file 1

Acknowledgements

We acknowledge the Dr Vinayak Kamath for providing statistical support for the research.

\section{Authors' contributions}

Dr Shishir Ram Shetty: Concept, data collection, manuscript writing. SaadWahby Al Bayatti: manuscript writing. Prof. Natheer Hashim AlRawi: manuscript writing. Prof. AR Samsudin: manuscript writing. Prof Hesham Marei: data collection. Dr Raghavendra Shetty: manuscript writing. Prof Hossam Abdelatty Abdelmagyd: data collection. Dr Sesha Reddy: data collection. The author(s) read and approved the final manuscript.

Funding

No sources of funding.

Availability of data and materials

Submitted as supplementary material. Also available at figshare; doi 10.6084/ m9.figshare.13385141

\section{Declarations}

Ethics approval and consent to participate

Obtained (Ref. no. INT/COD/FR/006-2020).

Consent for publication

Obtained.

Competing interests

$\mathrm{NIL}$.

Author details

'Department of Oral and Craniofacial Health Sciences, College of Dental Medicine, University of Sharjah, Sharjah, United Arab Emirates. ${ }^{2}$ College of Dentistry, Gulf Medical University, Ajman, United Arab Emirates. ${ }^{3}$ College of Dentistry, Ajman University, Ajman, United Arab Emirates. 
Received: 16 December 2020 Accepted: 8 July 2021

\section{Published online: 14 July 2021}

\section{References}

1. Ghosh P, Kumarasekaran P, Sriraman G. Incidence of accessory ostia in patients with chronic maxillary sinusitis. Int J Otorhinolaryngol Head Neck Surg. 2018;4(2):443-47.

2. Gutman $M$, Houser $S$. latrogenic maxillary sinus recirculation and beyond. Ear Nose Throat J. 2003;82(1):61-3.

3. Chung SK, Dhong HJ, Na DG. Mucus circulation between accessory ostium and natural ostium of maxillary sinus. J Laryngol Otol. 1999;113(9):865-67.

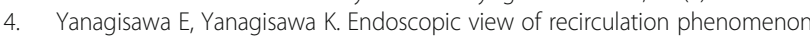
of the maxillary sinus. Ear Nose Throat J. 1997;76:196-98.

5. Mladina R, Vuković K, Poje G. The two holes syndrome. Am J Rhinol Allergy. 2009;23(6):602-04.

6. Yenigun A, Fazliogullari Z, Gun C, Uysal II, Nayman A, Karabulut AK. The effect of the presence of the accessory maxillary ostium on the maxillary sinus. Eur Arch Otorhinolaryngol. 2016;273(12):4315-19.

7. Bani-Ata M, Aleshawi A, Khatatbeh A, Al-Domaidat D, Alnussair B, AlShawaqfeh R, Allouh M. Accessory Maxillary Ostia: Prevalence of an Anatomical Variant and Association with Chronic Sinusitis. Int J Gen Med. 2020;13:163-8

8. Lechuga L, Weidlich GA. Cone Beam CT vs. Fan Beam CT: A Comparison of Image Quality and Dose Delivered Between Two Differing CT Imaging Modalities. Cureus. 2016;8(9):e778.

9. Butaric LN, Wadle M, Gascon J. Pediatric Imaging, Neurocognition and Genetics Study. Anatomical Variation in Maxillary Sinus Ostium Positioning: Implications for Nasal-Sinus Disease. Anat Rec (Hoboken). 2019;302(6):917-30.

10. Hung K, Montalvao C, Yeung AWK, Li G, Bornstein MM. Frequency, location, and morphology of accessory maxillary sinus ostia: a retrospective study using cone beam computed tomography (CBCT). Surg Radiol Anat. 2020; 42(2):219-28.

11. Sheikhi M, Pozve NJ, Khorrami L. Using cone beam computed tomography to detect the relationship between the periodontal bone loss and mucosal thickening of the maxillary sinus. Dent Res J (Isfahan). 2014;11(4):495-501.

12. Gu Y, Sun C, Wu D, Zhu Q, Leng, Zhou Y. Evaluation of the relationship between maxillary posterior teeth and the maxillary sinus floor using conebeam computed tomography. BMC Oral Health. 2018;189(1):164.

13. Asaumi R, Sato I, Miwa Y, Imura K, Sunohara M, Kawai T, et al. Understanding the formation of maxillary sinus in Japanese human foetuses using cone beam CT. Surg Radiol Anat. 2010;32(8):745-51.

14. Earwaker J. Anatomic Variants in Sinonasal CT. RadioGraphics. 1993;13(2): $381-415$.

15. Singhal $M$, Singhal $D$. Anatomy of accessory maxillary sinus ostium with clinical application. Int J Med Sci Public Health. 2014;3(3):327-29.

16. Genc S, Ozcan M, Titiz A, Unal A. Development of maxillary accessory ostium following sinusitis in rabbits. Rhinology. 2008;46(2):121-24.

17. Varadharajan R, Sahithya S, Venkatesan R, Gunasekaran A, Suresh S. An endoscopic study on the prevalence of the accessory maxillary ostium in chronic sinusitis patients. Int J Otorhinolaryngol Head Neck Surg. 2020;6(1):40-4.

18. Mahajan A, Mahajan A, Gupta K, Verma P, Lalit M. Anatomical variations of accessory maxillary sinus ostium: an endoscopic study. Int J Anat Res. 2017; 5(1):3485-90.

19. Gursoy M, Erdogan N, Cetinoglu YK, Dag F, Eren E, Uluc ME. Anatomic variations associated with antrochoanal polyps. Niger J Clin Pract. 2019; 22(5):603-8

20. Kakade AG, Chaudhari NH, Baviskar SM, Bagga RR, Patni ZM. Evaluation of Variations of Maxillary Sinus on Computed Tomography. MVP J Med Sci. 2018;5(2):172-7.

21. Prasanna LC, Mamatha H. H. The Location of Maxillary Sinus Ostium and Its Clinical Application. Indian J Otolaryngol Head Neck Surg. 2010;62(4):335-7.

22. Nayak JN, Varalakshmi KL, Sangeetha M, Naik S. An anatomical study on location of maxillary sinus ostium and it' s surgical importance. Int J Current Res Rev. 2014;6(18):7-9.

23. Patil M. KY M. Ostium maxillare accessorium - a morphologic study. Nat J Clin Ana. 2012;1(4):171-5.

24. Sindel A, Turhan M, Ogut E, Akdag M, Bostancı A, Sindel M. An endoscopic cadaveric study: Accessory maxillary ostia. Dicle Med J. 2014:41(2):262-7.

25. Ali IK, Sansare K, Karjodkar RR, Vanga K, Salve P, Pawar AM. Cone-beam computed tomography analysis of accessory maxillary ostium and Haller cells: Prevalence and clinical significance. Imaging Sci Dent. 2017;47(1):33-7.
26. Dedeoğlu N, Altun O. Evaluation of maxillary sinus anatomical variations and pathologies in elderly, young, posterior dentate and edentulous patient groups with cone-beam computed tomography. Folia Morphol. 2019;78(3): $595-9$.

27. Almutairi S. A Cadaveric Study on the Efficacy of Surface Marking and Bony Landmarks Used in Sacral Neuromodulation. Cureus. 2020;12(7):e9153.

28. Benchoufiab M, Matzner-Loberc, Molinari N, Jannot AS, Soyer P. Interobserver agreement issues in radiology. Diagn Interv Imaging. 2020; 101(10):639-41.

29. Hussein A. The association of maxillary accessory ostia with chronic rhinosinusitis what is essential; ventilation or drainage. Life Sci J. 2013;10(1): 2958-66.

30. Sahin C, Ozcan M, Unal A. Relationship between development of accessory maxillary sinus and chronic sinusitis. Med J DY Patil Univ. 2015;8(5):606-8.

31. Chung YS, Choi JM, Shin DH, Kim YW, Jeong KH, Cho JH, et al. Does Nasal Polyps Influence on the Location of Nasal Fontanelle? Kor J Otorhinolaryngol-Head Neck Surg. 2014;57(1):27-31.

32. Jankowski R, Rumeau C, Nguyen DT, Gallet P. Maxillary sinus pain with radiolucent sinuses due to agenesis of the membranous ostium. Eur Ann Otorhinolaryngol Head Neck Dis. 2019;136(1):43-6.

33. Ho JPK, Wong E, Singh NP. Bilateral Chronic Maxillary Atelectasis with a Unilateral Accessory Ostium. Eur J Rhinol Allergy. 2020;3(1):23-5.

34. Şimşek Kaya G, Daltaban Ö, Kaya M, Kocabalkan B, Sindel A, Akdağ M. The potential clinical relevance of anatomical structures and variations of the maxillary sinus for planned sinus floor elevation procedures: A retrospective cone beam computed tomography study. Clin Implant Dent Relat Res. 2019;21(1):114-21.

35. Souza AD, Rajagopal KV, Ankolekar VH, Souza AD, Kotian SR. Anatomy of maxillary sinus and its ostium: a radiological study using computed tomography. CHRISMED J Health Res. 2016;3(1):37-40.

36. El-Shazly AE, Poirrier AL, Cabay J, Lefebvre PP. Anatomical variations of the lateral nasal wall: The secondary and accessory middle turbinates. Clin Anat. 2012;25(3):340-6.

37. Yoon JH, Kim KS, Jung DH, Kim SS, Koh KS, Oh CS, et al. Fontanelle and uncinate process in the lateral wall of the human nasal cavity. Laryngoscope. 2000;110(2 Pt 1):281-5.

38. Kiruba LN, Gupta C, Kumar S, D'Souza AS. A study of morphometric evaluation of the maxillary sinuses in normal subjects using computer tomography images. Arch Med Health Sci. 2014;2:12-5.

39. Ryu J, Choi SH, Cha JY, Lee KJ, Hwang CJ. Retrospective study of maxillary sinus dimensions and pneumatization in adult patients with an anterior open bite. Am J Orthod Dentofacial Orthop. 2016;150(5):796-801.

40. Navarro JC, de Lima Navarro J, de Lima Navarro P. Lateral Wall of the Nasal Cavity. In: The Nasal Cavity and Paranasal Sinuses. Berlin: Springer; 2001. pp. 37-53.

41. Carmeli G, Artzi Z, Kozlovsky A, Segev Y, Landsberg R. Antral computerized tomography pre-operative evaluation: relationship between mucosal thickening and maxillary sinus function. Clin Oral Implants Res. 2011;22(1):78-82.

42. Okuyemi KS, Tsue $\Pi$. Radiologic imaging in the management of sinusitis. Am Fam Physician. 2002;66(10):1882-6.

43. Drumond JP, Allegro BB, Novo NF, de Miranda SL, Sendyk WR. Evaluation of the prevalence of maxillary sinuses abnormalities through spiral computed tomography (CT). Int Arch Otorhinolaryngol. 2017;21(2):126-33.

44. Maillet M, Bowles WR, McClanahan SL, John MT, Ahmad M. Cone-beam computed tomography evaluation of maxillary sinusitis. J Endod. 2011:37(6):753-7.

45. Tadinada A, Fung K, Thacker S, Mahdian M, Jadhav A, Schincaglia GP. Radiographic evaluation of the maxillary sinus prior to dental implant therapy: A comparison between two-dimensional and three-dimensional radiographic imaging. Imaging Sci Dent. 2015;45(3):169-74.

46. Yoshiura K, Ban S, Hijiya T, Yuasa K, Miwa K, Ariji E, Tabata O, Araki K, Tanaka $\mathrm{T}$, Yonetsu $\mathrm{K}$, et al. Analysis of maxillary sinusitis using computed tomography. Dentomaxillofac Radiol. 1993;22(2):86-92.

47. Iwamoto M, Watanabe M, Yamamoto M, Narita M, Kamio T, Takaki T, Shibahara T, Katakura A. Prognostic factors for maxillary sinus mucosal thickening following Le Fort I osteotomy: a retrospective analysis. Maxillofac Plast Reconstr Surg. 2019;41(1):12

48. Rak KM, Newell JD 2nd, Yakes WF, Damiano MA, Luethke JM. Paranasal sinuses on MR images of the brain: significance of mucosal thickening. AJR Am J Roentgenol. 1991;156(2):381-4.

49. Hansen AG, Helvik AS, Nordgård S, Bugten V, Stovner U, Håberg AK, Gårseth $M$, Eggesbø HB. Incidental findings in MRI of the paranasal sinuses in adults: 
a population-based study (HUNT MRI). BMC Ear Nose Throat Disord. 2014; 25(1):13. 14(.

50. Costa F, Emanuelli E, Robiony M. Incidence of maxillary sinus disease before sinus floor elevation surgery as identified by cone-beam computed tomography: a literature review. J Oral Implantol. 2018;44(2):161-6.

51. Capelli M, Gatti P. Radiological study of maxillary sinus using CBCT: relationship between mucosal thickening and common anatomic variants in chronic rhinosinusitis. J Clin Diagn Res. 2016;10(11):MC07-10.

\section{Publisher's Note}

Springer Nature remains neutral with regard to jurisdictional claims in published maps and institutional affiliations.

Ready to submit your research? Choose BMC and benefit from:

- fast, convenient online submission

- thorough peer review by experienced researchers in your field

- rapid publication on acceptance

- support for research data, including large and complex data types

- gold Open Access which fosters wider collaboration and increased citations

- maximum visibility for your research: over $100 \mathrm{M}$ website views per year

At BMC, research is always in progress.

Learn more biomedcentral.com/submissions 